\section{Aplikasi Bauran Promosi Pada Hotel Royal Padjadjaran Bogor}

\author{
Chairunisa Febriani, Yulia Nurendah dan Morita \\ Program Studi Manajemen Pemasaran D III, Institut Bisnis dan Informatika Kesatuan \\ Bogor, Indonesia \\ E - Mail : chairunisa@ibik.ac.id
}

Implementation of

Promotion Mix in

Hotel Industry

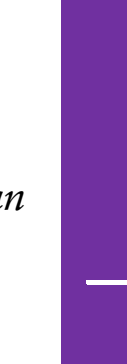

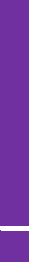

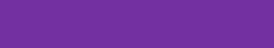

\begin{abstract}
Promotion is one of the most important strategies in marketing Products or Services, because the main purpose of promotion is so that the products or services offered by the Company can be known and recognized by a wide audience. promotion includes several elements consisting of Advertising, Public Relations, Sales Promotion, Personal Selling, and Direct Marketing. The five combinations of these elements are referred to as the Promotional Mix. Many companies carry out promotional activities not only from one element, this is intended so that promotions can be carried out as much as possible so that the company's goals are achieved. one of them is the Royal Padjadjaran Hotel Bogor which implements the Promotional Mix. The purpose of writing this Final Project is to find out what Promotional Mix is applied by Hotel Royal Padjadjaran Bogor, to find out what obstacles are faced in the implementation of the promotional mix carried out by Hotel Royal Pajajaran Bogor, and also to find out how to overcome obstacles in implementing the promotional mix. conducted by Hotel Royal Pajajaran Bogor. The results of the discussion show that the Promotional Mix carried out by Hotel Royal Padjadjaran Bogor has been implemented well, especially in implementing promotions through social media.
\end{abstract}

Keywords : Promotional Mix, Hotel Royal Padjadjaran Bogor

\begin{abstract}
ABSTRAK
Promosi merupakan salah satu strategi yang sangat penting di dalam memasarkan Produk atau Jasa, karena tujuan utama dari promosi yaitu agar produk atau jasa yang ditawarkan oleh Perusahaan dapat diketahui dan dikenal oleh khalayak luas. promosi mencakup beberapa elemen yang terdiri dari Advertising (Periklanan), Public Relation (Hubungan Masyarakat), Sales Promotion (Promosi Penjualan), Personal Selling (Penjualan Personal), dan Direct Marketing (Pemasaran Langsung). Ke lima kombinasi dari elemen ini disebut sebagai Bauran Promosi. Banyak Perusahaan melakukan kegiatan promosi tidak hanya dari satu elemen saja, hal ini dimaksudkan agar promosi yang dilakukan bisa semaksimal mungkin sehingga tujuan Perusahaan tercapai. salah satunya Hotel Royal Padjadjaran Bogor yang menerapkan Bauran Promosi. Tujuan penulisan Tugas Akhir ini untuk mengetahui Bauran Promosi apa saja yang diterapkan oleh Hotel Royal Padjadjaran Bogor, untuk mengetahui hambatan apa saja yang dihadapi dalam penerapan bauran promosi yang dilakukan oleh Hotel Royal Pajajaran Bogor, dan juga untuk mengetahui cara mengatasi hambatan dalam penerapan bauran promosi yang dilakukan oleh Hotel Royal Pajajaran Bogor. Hasil pembahasan menunjukkan bahwa Bauran Promosi yang dilakukan oleh Hotel Royal Padjadjaran Bogor sudah diterapkan dengan baik, terutama dalam menerapkan promosi melalui media sosial.
\end{abstract}

Kata kunci : Bauran Promosi, Hotel Royal Padjadjaran Bogor

\section{PENDAHULUAN}

Di era 4.0 yang semakin berkembang pesat, menyebabkan segala aspek mengalami perubahan. Salah satu yang mengalami perubahan adalah sektor pariwisata.

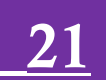

Submitted

JANUARI 2021

Accepted

JULI 2021

\section{JABKES}


Implementation Promotion Mix in Hotel Industry

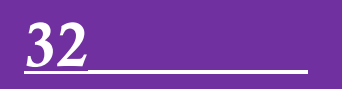

Perkembangan sektor pariwisata menjanjikan dan memberikan manfaat kepada banyak pihak, mulai dari pemerintah, masyarakat, maupun swasta. Hal ini dikarenakan pariwisata merupakan sektor yang menguntungkan untuk dikembangkan, sebagai salah satu aset yang menjanjikan bagi pemerintah maupun masyarakat. Oleh karena itu membuat banyak daerah berkeinginan untuk mengadakan pembangunan di sektor pariwisata. Salah satu contohnya adalah perkembangan bisnis perhotelan di Indonesia. Perkembangan bisnis perhotelan di Indonesia mengalami peningkatan yang cukup signifikan. Peningkatan tersebut dapat dilihat berdasarkan meningkatnya jumlah kunjungan wisatawan di Indonesia dan pertumbuhan industri pariwisata termasuk bertumbuhnya jumlah hotel di Indonesia.

Badan Pusat Statistik (BPS) mencatat, kunjungan wisatawan mancanegara (wisman) ke Indonesia meningkat sejak Juni 2019. Hal tersebut merupakan kabar yang menggembirakan setelah sempat mengalami penurunan pada bulan Mei sebesar 2,97\% dari 1,3 juta kunjungan menjadi 1,26 juta kunjungan.Pada bulan Juni 2019, angka kunjungan wisman melonjak 15,48\% menjadi 1,45 juta kunjungan. Pada bulan Juli 2019, kunjungan wisman kembali meningkat 2,04\% menjadi 1,48 juta kunjungan. Data terakhir pada Agustus 2019, kunjungan wisman mencapai 1,56 juta kunjungan atau meningkat $4,83 \%$ dibandingkan bulan sebelumnya. Secara tahunan, kunjungan wisman naik 2,94\% dibandingkan Agustus 2018 yang sebesar 1,5 juta kunjungan.Wisman yang berkunjung paling banyak datang melalui jalur pintu udara sebanyak 992 ribu kunjungan. Sementara itu, wisman yang datang dari jalur pintu laut sebanyak 371,5 ribu dan pintu darat sebanyak 192 ribu kunjungan.

(https://databoks.katadata.co.id/datapublish/2019/10/02/kunjungan-wisatawanmancanegara-naik-tiga-bulan-berturut-turut diakses pada tanggal 7 Februari 2020)

Untuk perkembangan perhotelan di Bogor itu sendiri juga mengalami perkembangan pesat. Sebagaimana yang diketahui bahwa Bogor merupakan salah satu kota yang cukup sering dikunjungi oleh para wisatawan baik dari dalam maupun luar negeri. Bogor dijadikan tempat untuk berwisata. Selain itu, Bogor juga menjadi kota yang strategis, karena dekat dengan Jakarta yang merupakan kota sebagai pusat bisnis dan pemerintahan. Menurut catatan HVS, penyedia data perhotelan global, sampai akhir 2014 , terdapat 17 hotel berbintang baik berasal dari jaringan lokal, maupun internasional. Jumlah ini terus bertambah menjadi dua kali lipatnya pada 2016 mendatang menjadi 32 hotel dengan 2.969 kamar. Data HVS juga menyebutkan Compound Annual Growth Rate (CAGR) hotel di Bogor sebesar 40 persen selama periode enam tahun, mulai 2011 hingga 2016. Pasar hotel Bogor sendiri didominasi pengunjung domestik dari total 1,78 juta pengunjung. Terutama pengunjung yang berasal dari Jakarta yang menguasai sebesar 90 persen, dan wilayah penyangga lainnya sebanyak 2 persen. Sementara turis asing berasal dari Singapura, Jepang, Belanda, dan Tiongkok dengan posisi 4 persen. Ada pun sejumlah 4 persen sisanya berasal dari negara-negara asing lainnya.(https://properti.kompas.com/read/2015/01/14/184604121/Pertumbuhan.Ho tel.Berbintang.di.Bogor.Dua.Kali.Lipat diakses pada tanggal 7 Februari 2020).

Banyaknya pembangunan hotel yang baru di Bogor memberikan konsekuensi adanya persaingan antara pengusaha hotel yang mengancam jumlah hunian. Persaingan tersebut dapat diatasi dengan penawaran-penawaran yang diberikan langsung oleh hotel dengan cara:

1. Menawarkan pengalaman unik kepada calon tamu hotel, misalnya melalui fitur yang diberikan, ataupun penawaran terkait promosi.

2. Jangan pernah perang harga, alih-alih bersaing pada harga, lebih baik bersaing pada nilai dan pengalaman yang diberikan kepada tamu.

3. Aktif di media sosial, media sosial merupakan alat pemasaran yang sangat efektif untuk bisnis perjalanan dan pariwisata. Hubungan baik dengan tamu melalui media sosial dapat menambah loyalitas tamu untuk terus menginap di hotel tersebut. Selain itu, melalui media sosial pengelola hotel juga bisa memberikan informasi berupa rekomendasi destinasi wisata yang dekat dengan lokasi hotel, dan kegiatan apa saja yang bisa dilakukan di destinasi wisata tersebut. 
4. Lakukan kerjasama dengan agen perjalanan wisata.

5. Temukan ceruk pasar yang cocok dengan hotel, dan dominasi ceruk tersebut

6. Gunakan kekuatan Email Marketing, Email Marketing merupakan salah satu alat pemasaran yang paling efektif untuk bisa meningkatkan okupansi hotel. (https://studipariwisata.com/referensi/strategi-marketing-hotel// diakses pada tanggal 8 Februari 2020).

Ketatnya persaingan antara hotel-hotel yang ada di Bogor, ini menuntut setiap perusahaan harus melakukan terobosan-terobosan, demi menarik minat konsumen dan agar mampu bersaing dipasaran. terobosan yang dapat dilakukan meliputi jasa layanan yang diberikan, harga yang ditawarkan, kemudahan akses, dan lain sebagainya. Hal lain yang dapat dilakukan adalah melalui kegiatan promosi. Kegiatan promosi merupakan salah satu komponen yang menjadi prioritas dari kegiatan pemasaran. Dengan adanya promosi maka konsumen akan mengetahui bahwa perusahaan meluncurkan produk/jasa baru yang akan menggoda konsumen untuk melakukan kegiatan pembelian. Sebelum melakukan kegiatan promosi, perusahaan harus memilih jenis bauran promosi apa yang akan digunakan. Banyak yang mengatakan bahwa kegiatan promosi identik dengan dana yang dimiliki oleh perusahaan. Semakin besar dana yang dimiliki oleh suatu perusahaan umumnya akan menghasilkan promosi yang juga sangat gencar. Tetapi disamping itu, dana yang terbatas dapat diatasi dengan inovasi yang lebih cerdas dan tepat.

Kegiatan promosi sangat erat kaitannya dengan penyebaran informasi untuk disampaikan ke konsumen. dalam penyampaian informasi ini ada beberapa hal penting yang hendaknya diperhatikan, yaitu :

1. Program periklanan yang dijalankan, kegiatan periklanan merupakan media utama bagi perusahaan untuk menunjang kegiatan promosi dimana promosi memiliki tujuan utama untuk menarik konsumen agar mau melakukan pembelian terhadap produk atau jasa yang ditawarkan. Media yang sering digunakan dalam periklanan saat ini adalah media cetak dan elektronik.

dunia periklanan sendiri telah mengalami perkembangan yang amat pesat. Salah satunya adalah dengan mulai maraknya iklan melalui internet.

2. Promosi dengan mengutamakan penjualan yang dilakukan secara pribaadi, atau biasa dikenal dengan istilah 'penjualan personal (personal selling)'. Kegiatan promosi yang satu ini bisa dikatakan sebagai ujung tombak dari kegiatan promosi. Hal ini karena penjualan personal adalah kegiatan promosi yang mengharuskan pemasar berhadapan dengan konsumen secara langsung. Kegiatan penjualan personal yang dilakukan secara profesional akan sangat membantu tercapainya penjualan secara fantastis.

3. Promosi yang dilakukan dengan mengedepankan aspek penambahan intensitas nilai produk (additional values of product) dalam strategi pemasaran dikenal sebagai promosi penjualan (sales promotion). Promosi penjualan mengedepankan penambahan intensitas nilai barang/jasa. Hal ini meliputi berbagai aspek manajemen pemasaran, mulai dari peningkatan kualitas produk, kualitas pelayanan distribusi bagi distributor, meningkatkan kualitas pelayanan bagi pelanggan agar menjadi lebih baik dan masih banyak aspek lainnya yang dapat ditingkatkan demi tercapainya kepuasan pelanggan. Secara khusus program-program promosi penjualan meliputi diskon, rabat, bantuan pembiayaan periklanan, dan bonus bagi dealer/agen dan sebagainya.

4. Promosi dengan cara meningkatkan publisitas, cara ini lebih condong untuk membentuk sebuah citra yang lebih positif terhadap produk/jasa yang ditawarkan. Pembentukan citra yang positif ini dapat dilakukan dengan iklan atau promosi yang memiliki karakteristik tertentu yang tidak dapat dimiliki oleh strategi pemasaran lainnya. Bisa saja dilakukan dengan cara menciptakan suatu produk yang memiliki point lebih, karakteristik unik, atau mempunyai manfaat lebih yang dapat menjadi citra positif dihadapan konsumen. jika hal ini dapat dilakukan maka citra atau gambaran positif yang berkembang di masyarakat akan terbentuk dan mendatangkan beberapa faktor positif untuk mendongkrak penjualan. 
Keempat komponen tersebut harus dapat dilakukan secara sinkron agar dapat menghasilkan strategi pemasaran yang baik dalam jangka panjang. Secara teoritis terdapat 8 macam bauran promosi yang terdiri dari periklanan (Advertising), penjualan personal (Personal Selling), promosi penjualan (Sales Promotion), hubungan masyarakat (Public Relation), pemasaran langsung (Direct Marketing), pemasaran secara lisan (Word Of Mouth), Digital Marketing, dan Event and Sponsorship.

\section{Identifikasi Masalah}

1. Bauran promosi apa saja yang diterapkan oleh Hotel Royal Pajajaran Bogor?

2. Hambatan apa saja yang dihadapi dalam penerapan bauran promosi yang dilakukan oleh Hotel Royal Pajajaran Bogor?

3. Bagaimana cara mengatasi hambatan dalam penerapan bauran promosi yang dilakukan oleh Hotel Royal Pajajaran Bogor?

\section{Tujuan Penelitian}

1. Untuk mengetahui bauran promosi apa saja yang diterapkan oleh Hotel Royal Pajajaran Bogor.

2. Untuk mengetahui hambatan apa saja yang dihadapi dalam penerapan bauran promosi yang dilakukan oleh Hotel Royal Pajajaran Bogor.

3. Untuk mengetahui cara mengatasi hambatan dalam penerapan bauran promosi yang dilakukan oleh Hotel Royal Pajajaran Bogor.

\section{HASIL DAN PEMBAHASAN}

\section{Sejarah Perusahaan}

Sebelum dibangunnya Royal Padjadjaran Hotel adalah sebuah bangunan berupa Cafe atau Billiard Center. Tidak lama kemudian tempat tersebut dibeli oleh sebuah perusahaan yang bernama PT. Grand Royal Padjadjaran dan bangunan tersebut dibangun kembali menjadi sebuah bangunan yang didirikan oleh seorang pengusaha yang bernama $\mathrm{Ny}$. Nariman yang berasal dari Saudi Arabia, dan dibangun sebuah gedung hotel berbintang 4 yang diberi nama Hotel Royal Padjadjaran yang dibuka pada tanggal 24 Agustus 2015.

Hotel Royal Padjadjaran Bogor merupakan hotel yang berada di lokasi yang baik, tepatnya di Jalan Raya Padjadjaran No. 12, kelurahan babakan, kecamatan Bogor Tengah, kota Bogor. Letaknya yang strategis membuat hotel ini menjadi buruan pengunjung dan menjadi salah satu rekomendasi hotel terbaik. 


\section{Struktur Organisasi dan Uraian Tugas}

Berikut Struktur Organisasi Hotel Royal Padjadjaran Bogor beserta uraian tugas masing-masing Departemen :

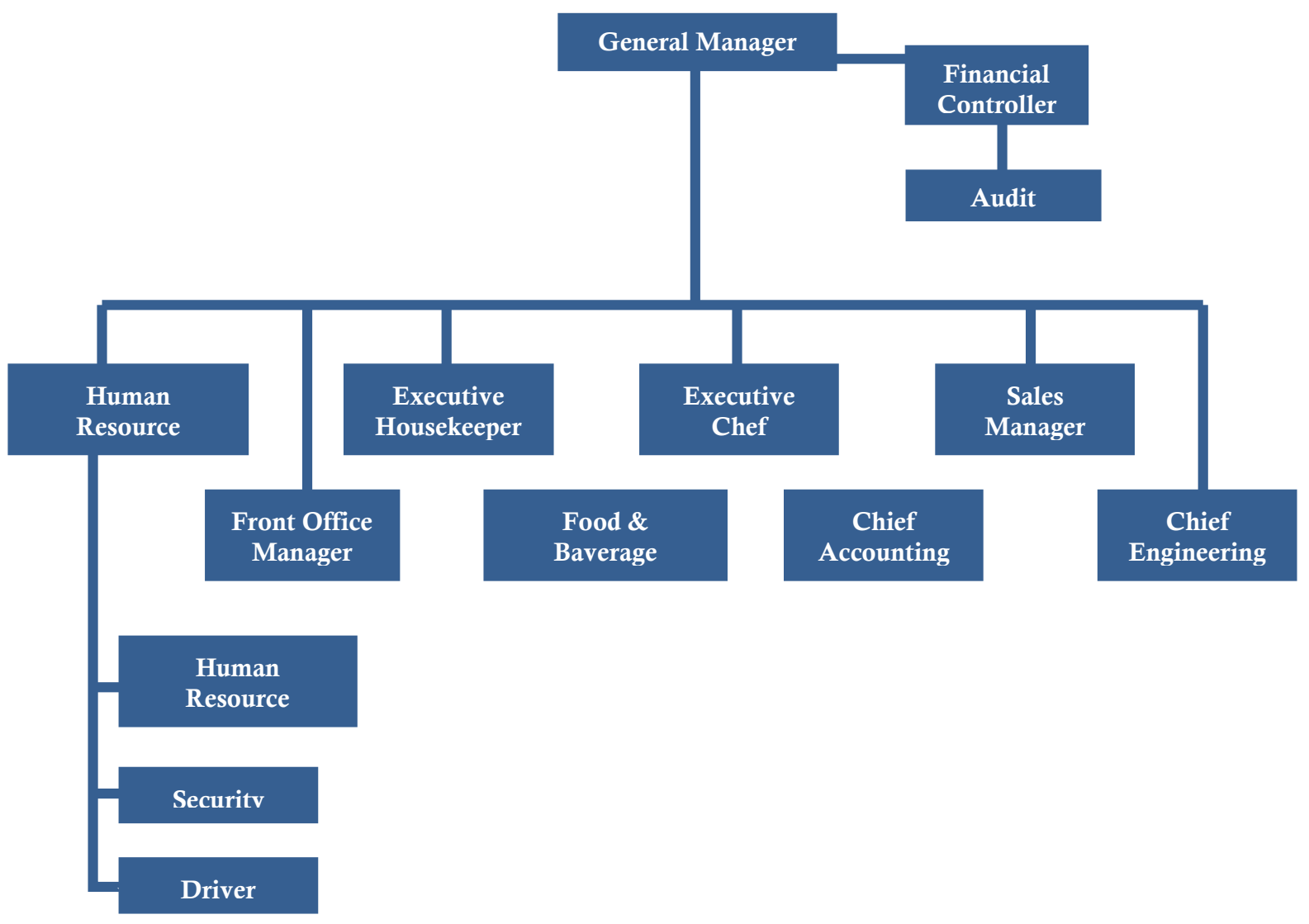

\section{Gambar 1. Struktur Organisasi Hotel Royal Padjadjaran Bogor}

1. General Manager: Memimpin Hotel dan menjadi fasilitator bagi seluruh karyawannya disemua level jabatan diunit Hotel.

2. Financial Controller: Seorang Financial Controller bertanggung jawab pada keuangan milik Hotel, Peran dan fungsinya yaitu menjaga sistem akuntansi perusahaan, berpartisipasi dalam menyusun anggaran.

3. Audit Officer: Tugas Unit Audit Internal adalah menyusun dan melaksanakan rencana dan anggaran Aktivitas Audit Internal Tahunan, dan melakukan pemeriksaan dan penilaian atas efisiensi dan efektivitas diseluruh bidang kegiatan Perseroan. (https://stptower.com/audit-internal/ diakses pada tanggal 09 Juni 2020).

4. DepartmentHuman Resource

a. Human Resource Manager: Tugas seorang Manajer Sumber Daya Manusia adalah mempertahankan struktur kerja dengan memperbaharui persyaratan pekerjaan dan deskripsi pekerjaan untuk semua posisi, dan menjaga staf organisasi dengan membentuk program Rekrutmen, pengujian, dan wawancara.

b. Human Resource Officer: Tugas dan tanggung jawab HRD meliputi kegiatan Administrasi kepegawaian, dan juga menjalin kerjasama dengan sekolah maupun universitas untuk kebutuhan siswa Training.

c. Security: Tugas security Hotel ialah membuat laporan harian, meliputi kegiatan pengecekan transportasi yang digunakan oleh tamu hotel, dan jumlah kunjungan tamu hotel, yang nantinya laporan tersebut akan diserahkan kepada bagian Human Resource Officer. 
d. Driver: Tugas Driver yaitu mengantar dan menjemput tamu hotel sesuai dengan reservasi yang dilakukannya.

5. Department Front Office

a. Front Office Manager: Tugas Front Office Manager adalah memastikan bahwa pekerjaan dari seorang Front Office berjalan dengan baik. (https://www.jojonomic.com/blog/front-office-manager/diakses pada tanggal 09 Juni 2020).

b. Front Office Staff: Tugas Front Office Hotel adalah menerima dan menangani pemesanan kamar oleh calon Customer, melakukan konfirmasi pemesanan ulang, mengurus bill pembayaran tamu selama menginap di Hotel, memberikan pelayanan informasi. (https://olympics30.com/tugas-front-office/ diakses pada tanggal 09 Juni 2020).

6. Department Housekeeping

a. Executive Housekeeper: Menyusun dan menyiapkan program kerja, anggaran dan Standart Operating Procedure Housekeeping, memberi arahan terhadap tugas-tugas yang harus dilakukan karyawan dibagian Housekeeping.

7. Department Food \& Baverage

a. Food \& Baverage Manager: Secara garis besar tanggung jawab dan tugas- tugas seorang Food and Baverage Service Manager adalah mengkoordinasikan kegiatan dan operasional Food and Baverage Service, kemudian bertanggung jawab dan mengawasi semua kegiatan Food and Baverage Service, serta menangani masalah yang tidak bisa diatasi oleh bawahan.(https://www.slideshare.net/AsriNurArsy/food-and-beveragepresentasi diakses pada tanggal 09 Juni 2020).

8. Executive Chef: Bertanggung jawab atas tugas-tugas dan bahan pangan yang menjadi bagian dalam penjualan berdasarkan standar operasional kitchen itu sendiri.

9. Department Accounting

a. Chief Accounting : Bertugas dalam mengkoordinasikan operasional penyusunan laporan keuangan milik Hotel baik bulanan maupun tahunan.

10. Sales Manager :Menerima dan melakukan follow up event, melakukan sales call dan Telemarketing.

a. Sales Executive : Bertanggung jawab atas event yang sedang berlangsung, mengawasi jalannya persiapan yang dilakukan oleh masing-masing Departemen sebelum event berlangsung.

11. Department Engineering

a. Chief Engineering : Merupakan penanggung jawab dalam melaksanakan dan mengontrol kegiatan Engineering.

\section{Sumber Daya Manusia}

Karyawan dibagian divisi Human Resource Development (HRD) berjumlah 8 tenaga karyawan. Satu diantaranya sebagai Human Resource Manager atau Manajer HRD, yang menaungi Human Resource Officer atau Admin HRD, Security, serta Driver. Admin HRD berjumlah 1 orang, Security berjumlah 3 orang, dan Driver berjumlah 3 orang. Sehingga totalnya ada 8 (delapan) tenaga karyawan. Untuk tingkat pendidikan karyawan mulai dari lulusan SMA, D3 dan S1.

\section{Sarana dan Prasarana}

Hotel Royal Padjadjaran Bogor memiliki sarana sebagai berikut :

1. Terdiri dari sembilan (9) lantai.

2. Basment atau tempat parkir untuk mobil dan motor dilantai G.

3. Musholla dan loker untuk karyawan atau petugas hotel.

4. Lobby dan terdepat Front Office untuk menyambut tamu,

5. Buitenzorg Restoran

6. Kolam renang, 


\section{Kids Station,}

8. Musholla untuk para tamu hotel.

9. Passer Restoran

10. Meeting Room (ruang meeting Pakuan dan Siliwangi).

11. Kemudian dari lantai 3 sampai dengan lantai 8 itu terdapat kamar untuk tamu totalnya ada 106 kamar. dan di lantai 9 terdapat Meeting Room (ruang meeting padjadjaran).

Hotel Royal Padjadjaran Bogor memiliki prasarana sebagai berikut :

1. Komputer, digunakan untuk mendukung kegiatan kerja. Hampir seluruh divisi menggunakan komputer agar mempermudah kegiatan kerja serta berfungsi untuk menyimpan data-data pribadi hotel.

2. AC disetiap ruangan, baik itu ruangan kerja/tiap divisi maupun kamar Hotel.

3. Tersedia berbagai Furniture seperti meja, kursi, kaca hias, serta hiasan interior lainnya yang mampu menghidupkan suasana setiap sudut Hotel. dan juga tersedia mobil untuk antar jemput tamu Hotel.

\section{Uraian Singkat Kegiatan Magang}

Kegiatan magang dimulai pada tanggal 24 Februari 2020 sampai dengan 20 Maret 2020. Masuk pukul 09.00 - 17.00 WIB. Uraian kegiatan yang dilakukan selama magang yaitu meliputi :

1. Filling dokumen-dokumen mulai dari Daily Security (laporan harian, meliputi kegiatan pengecekan transportasi yang digunakan oleh tamu Hotel, dan jumlah kunjungan tamu Hotel), kemudian Filling dokumen hasil Morning Briefing, dan tiap dokumen disesuaikan dengan nomor ISO.

2. Latihan membuat rekap absen anak training (magang), dan juga disesuaikan dengan nomor ISO.

3. Latihan membuat Form Daily worker, Public Holiday, Overtime, serta form cuti bagi karyawan Hotel.

4. Scan arsip yang dibutuhkan

5. Latihan membuat Internal Memo, yang kemudian akan dibagikan ke tiap Departemen/Divisi.

6. Membantu menyiapkan makan siang untuk anak magang.

Manfaat yang dapat diperoleh dari kegiatan magang ini cukup banyak, mulai dari halhal yang tidak pernah diketahui atau dipelajari sebelumnya terutama mengenai tugastugas atau Jobdesk dibagian HRD. Seperti bagaimana merekrut karyawan yang baik serta berkualitas yang dibutuhkan oleh perusahaan, kemudian bagaimana mendata serta filling dokumen-dokumen perusahaan. Selain itu, dengan adanya kegiatan magang ini menjadi ajang untuk menambah pengalaman kerja, memahami etika serta disiplin kerja yang sangat dibutuhkan sebelum memasuki dunia kerja.

\section{Perbandingan antara Teori dan Praktek}

\section{Bauran Promosi yang diterapkan oleh Hotel Royal Padjadjaran Bogor}

Bauran Promosi/Promotion Mix atau yang biasa dikenal juga dengan Bauran Komunikasi Pemasaran ini merupakan salah satu strategi di dalam Marketing yang paling sering digunakan oleh Perusahaan. Hal ini dimaksudkan agar tujuan Perusahaan dalam memasarkan Produk atau Jasa mampu terlaksana dengan baik dan juga mampu menaikkan volume penjualan. Untuk itu perusahaan sering menggunakan beberapa media promosi guna melakukan promosi semaksimal mungkin.

Menyesuaikan dengan teori yang ada, dalam penerapan Bauran Promosi Hotel Royal Padjadjaran Bogor hanya menerapkan beberapa elemen promosi saja. Artinya tidak semua elemen promosi digunakan, hanya beberapa saja. 
Adapun secara prakteknya, sesuai dengan tujuan promosi yaitu untuk menginformasikan, membujuk, serta mengingatkan kepada khalayak luas mengenai jasa yang ditawarkan oleh Hotel Royal Padjadjaran Bogor. untuk itu Hotel Royal menggunakan beberapa media untuk melakukan promosi guna menarik minat konsumen untuk menginap di Hotel Royal Padjadjaran Bogor. berikut media Promosi yang digunakan :

1. Digital Marketing, melalui Sosial Media meliputi Instagram, Facebook, Website, Twitter dengan nama akun masing-masing yaitu :
a. Instagram
: @royalpadjadjaranhotel
b. Facebook
: Royal Padjadjaran Hotel
c. Website
: http://royalpadjadjaranhotel.com
d. Twitter
: Royal Padjadjaran Hotel

Di samping itu Hotel juga melakukan promosi melalui Platform atau Online Travel Agent seperti Agoda, Traveloka, Pegi-Pegi, dan Tiket.com. disana Hotel menawarkan berbagai promo menarik yang mampu meningkatkan okupansi Hotel. selain mempromosikan fasilitas-fasilitas yang tersedia di Hotel, Hotel juga menawarkan berupa potongan harga/diskon di hari-hari atau momen penting seperti liburan awal tahun dan akhir tahun, Lebaran Idul Fitri, hari Raya Natal maupun Imlek, promo cashback, promo paket buka bersama pada saat bulan puasa, dan masih banyak lagi.

2. Berikut contoh promosi yang ditawarkan oleh Hotel :

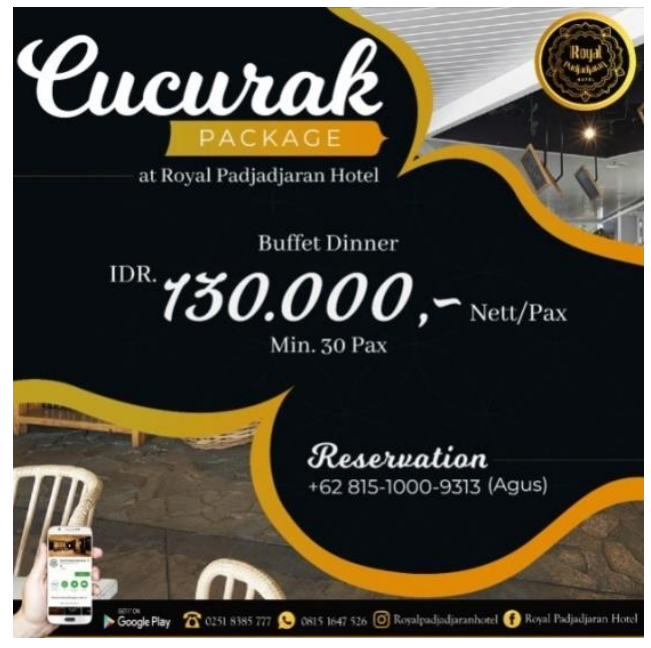

Gambar 2. Paket Promo Cucurak

Hotel Royal Padjadjaran Bogor menjalankan unit program CSR (Corporate Social Responsibility) atau Tanggung Jawab Sosial Perusahaan. Hal ini berdampak pada meningkatnya citra positif Hotel di lingkungan Masyarakat.

Di bawah ini adalah salah satu kegiatan yang pernah dilakukan oleh Hotel Royal pada saat memperingati Hari Menanam Pohon Se-Indonesia, dengan membagikan snack box. 


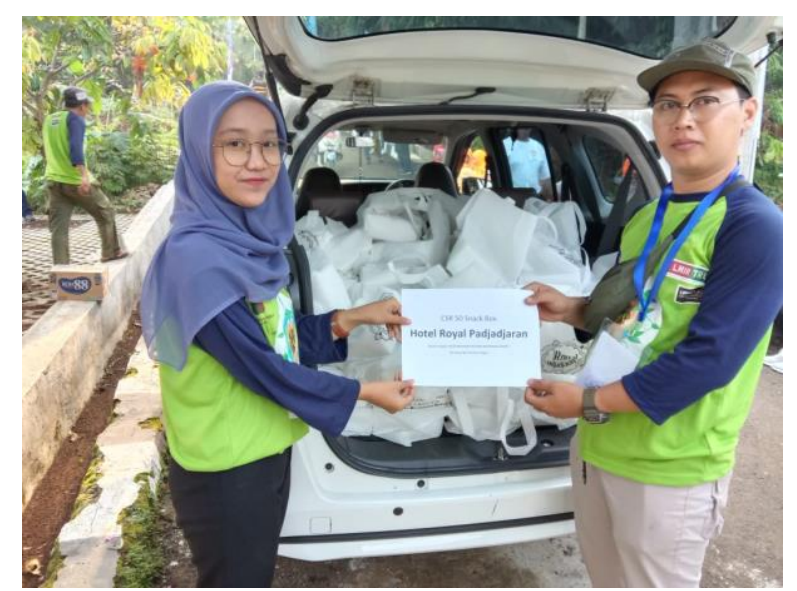

\section{Gambar 3. Salah Satu Kegiatan Program CSR}

\section{Hambatan yang dihadapi dalam Penerapan Bauran Promosi yang dilakukan oleh Hotel Royal Padjadjaran Bogor}

Dalam menerapkan bauran promosi, Hotel Royal Padjadjaran Bogor mengalami beberapa hmbatan. Berikut hambatan yang dihadapi dalam Penerapan Bauran Promosi yang dilakukan oleh Hotel Royal Padjadjaran Bogor:

1. Keterbatasan Anggaran Dana yang tersedia menjadikan penghambat dalam melakukan kegiatan promosi.

2. Kurangnya informasi berkenaan dengan keinginan konsumen terhadap fasilitasfasilitas yang ditawarkan oleh Hotel.

3. Promosi yang ditawarkan oleh pesaing lebih mampu menarik calon konsumen.

Cara mengatasi hambatan dalam Penerapan Bauran Promosi yang dilakukan oleh Hotel Royal Padjadjaran Bogor

Melihat adanya hambatan yang terjadi, maka Hotel memiliki cara untuk mengatasi hambatan tersebut. berikut cara mengatasi hambatan yang terjadi :

1. Terkait Anggaran, dilakukan mekanisme promosi tidak hanya dengan media cetak tetapi juga dengan media sosial atau Digital Marketing, yang mampu menjangkau khalayak lebih luas.

2. Melakukan riset untuk mengetahui fasilitas-fasilitas apa saja yang diharapkan oleh calon konsumen.

3. Menciptakan promosi yang berbeda dari pesaing, dengan menawarkan pengalaman unik seperti mengajak keliling tempat wisata yang ada di Bogor, yang tentunya sesuai dengan persyaratan dan ketentuan yang berlaku.

\section{PENUTUP}

Berdasarkan hasil tinjauan tersebut, maka dapat disimpulkan sebagai berikut :

1. Hotel Royal Padjadjaran Bogor menggunakan beberapa media untuk melakukan promosi guna menarik minat konsumen untuk berkunjung dan menginap, serta bertujuan untuk menaikan okupansi Hotel. berikut media Promosi yang digunakan :

a. Digital Marketing/menggunakan Media Sosial dalam mempromosikan Hotel. Media sosial yang digunakannya yaitu Instagram, Facebook, Website,Twitter. Selain itu Hotel juga melakukan promosi melalui Platform atau Online Travel Agent seperti Agoda, Traveloka, Pegi-Pegi, dan Tiket.com. disana Hotel menawarkan berbagai promo menarik mulai dari potongan harga/diskon di hari-hari atau momen penting seperti liburan awal tahun dan akhir tahun, Lebaran Idul Fitri, hari Raya Natal maupun Imlek, promo cashback, promo paket buka bersama pada saat bulan puasa, dan masih banyak lagi. 
b. Selain melakukan Promosi melalui Media Sosial dan Platform, Hotel Royal Padjadjaran Bogor juga menjalankan unit program CSR (Corporate Social Responsibility) atau Tanggung Jawab Sosial Perusahaan. Hal ini berdampak pada meningkatnya citra positif Hotel di lingkungan Masyarakat.

2. Di dalam menerapkan Bauran Promosi, Hotel Royal Padjadjaran Bogor mengalami beberapa hambatan. hambatan yang dihadapi dalam Penerapan Bauran Promosi yang dilakukan oleh Hotel Royal Padjadjaran Bogor meliputi Keterbatasan Anggaran Dana yang tersedia menjadikan penghambat dalam melakukan kegiatan promosi, kemudian Kurangnya informasi berkenaan dengan keinginan konsumen terhadap fasilitas-fasilitas yang ditawarkan oleh Hotel, dan Promosi yang ditawarkan oleh pesaing lebih mampu menarik calon konsumen.

3. Melihat adanya hambatan yang terjadi, maka Hotel memiliki cara untuk mengatasi hambatan tersebut. berikut cara-cara yang dimiliki oleh Hotel untuk mengatasi hambatan tersebut ialah terkait Anggaran, dilakukan mekanisme promosi tidak hanya dengan media cetak tetapi juga dengan media sosial atau Digital Marketing, yang mampu menjangkau khalayak lebih luas. kemudian terkait dengan kurangnya informasi berkenaan dengan fasilitas yang diinginkan oleh konsumen maka Hotel melakukan riset untuk mengetahui fasilitas-fasilitas apa saja yang diharapkan oleh calon konsumen. dan berkaitan dengan Promosi yang ditawarkan oleh pesaing, maka Hotel menciptakan promosi yang berbeda dari pesaing, dengan menawarkan pengalaman unik seperti mengajak keliling tempat wisata yang ada di Bogor, yang tentunya sesuai dengan persyaratan dan ketentuan yang berlaku.

\section{DAFTAR PUSTAKA}

Arifin, Pradina. 2016. Tinjauan Atas Aktivitas Direct Selling pada PT. Promedrahardjo Farmasi Industri.

Griffin, Ebert., 2015. Pengantar Bisnis, Edisi 10, Erlangga, Jakarta.

Hermawan, Agus ., 2012. Komunikasi Pemasaran,Erlangga, Jakarta.

Lovelock, C., Wirtz J. dan Mussry, J., 2010. Pemasaran Jasa. Edisi 7, Erlangga, Jakarta.

Lupiyoadi, R. dan Hamdani, A., 2006. Manajemen Pemasaran Jasa, Edisi 2, Salemba Empat, Jakarta.

Peter, J.P. dan Olson, J.C., 2014. Perilaku Konsumen \& Strategi Pemasaran, Edisi 9, Salemba Empat, Jakarta.

Setiyaningrum, A., Udaya J. Dan Efendi., 2015. Prinsip-prinsip Pemasaran, Andi Yogyakarta, Yogyakarta.

Tjiptono, Fandy Ph.D. dan Gregorius Chandra, S.E., 2017,Pemasaran Strategik, Edisi 3, Katalog Dalam Terbitan, Yogyakarta.

Kunjungan WisatawanMancanegara.[tersedia pada https://databoks.katadata.co.id ], diakses pada tanggal 7 Februari 2020.

Pertumbuhan Hotel Berbintang di Bogor.[tersedia pada https://properti.kompas.com], diakses pada tanggal 7 Februari 2020.

Strategi Marketing Hotel.[tersedia pada https://studipariwisata.com], diakses pada tanggal 8 Februari 2020).

Pengertian Marketing Mix.[https://www.maxmanroe.com], diakses pada tanggal 08 Februari 2020).

Bauran dan Strategi Komunikasi Pemasaran.[https://www.kajianpustaka.com], diakses pada tanggal 4Februari 2020.

Pengertian Digital Marketing. [https://www.domainesia.com], diakses pada tanggal 14 Juni 2020.

Tujuan Utama Digital Marketing.[https://www.dhadigital.com], diakses pada tanggal 14 Juni 2020.

Pengertian Event and Sponsorship. [https://slideplayer.info], diakses pada tanggal 5 Februari 2020. 
Pengertian front Office Manager.[https://www.jojonomic.com],diakses pada tanggal 09 Juni 2020.

Pengertian Front Office Staff. [https://olympics30.com], diakses pada tanggal 09 Juni 2020. Pengertian Food and Baverage. [https://www.slideshare.net], diakses pada tanggal 09 Juni 2020.

Pengertian Audit Internal.[https://stptower.com], diakses pada tanggal 09 Juni 2020. 